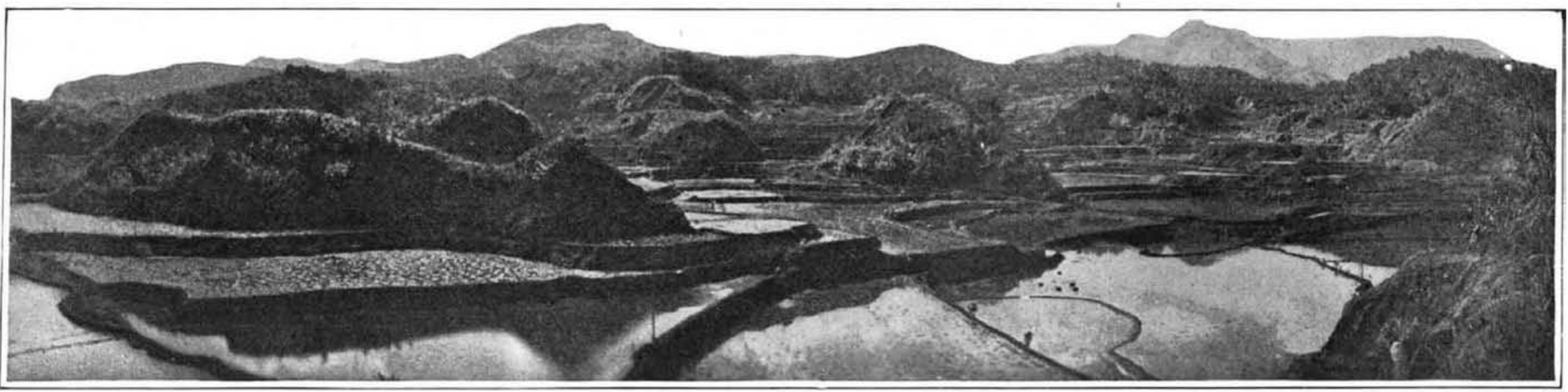

The rice terraces at the summit of the mountain.

\title{
Savage Irrigation in Luzon
}

The Wonderful Rice Terraces of the Head-hunting Ifugaos

By Hamilton W'right

With Photographs by the Author

A LMOST every traveler in the Orient in Japan, China, and the region of the in Japan, China, and the region of the straits Settlements. The system of terrac ing is noteworthy for the unique attraction it lends to the landscape and because it illustrates how every available bit of land is used to advantage in densely populated regions. The most wonderful terraces in the Orient, however, have been seen by but few people, and are practically unknown. These are the rice terraces of the Ifugaos, a tribe closely akin to the Igorrotes, and living in the northern portion of Nueva Viscaya Province in the heart of Luzon. The Ifugao terraces greatly surpass the better known and more easily reached terraces of the Igorrotes near Baguio, the Simla of the Philippines, and, it is said, there is nothing in Java or the Andes that can compare with them.

From an industrial view point the Ifugao terraces represent the most colossai undertakings in the Philippines, and perhaps the most s.tupendous task ever accomplished by a thoroughly savage people. viewing the terraces, one compares them with such works as the Pyramids or the great wall of China, or even with the Roman viaducts. In point of combined utility and engineering skill they compare in some respects with the Roman viaducts, although viewed in connection with the primitive condition of the people there is probably nothing comparable to them in the world. By way of contrast with like achievements of more civilized races, it should be mentioned that the Ifugaos are absolutely primitive, even lacking a system of writing and a well-defined religious belief. Their writing up to the time when the American school teacher invaded the country consisted of a few rude hieroglyphics scratched on a rock or in the sand.

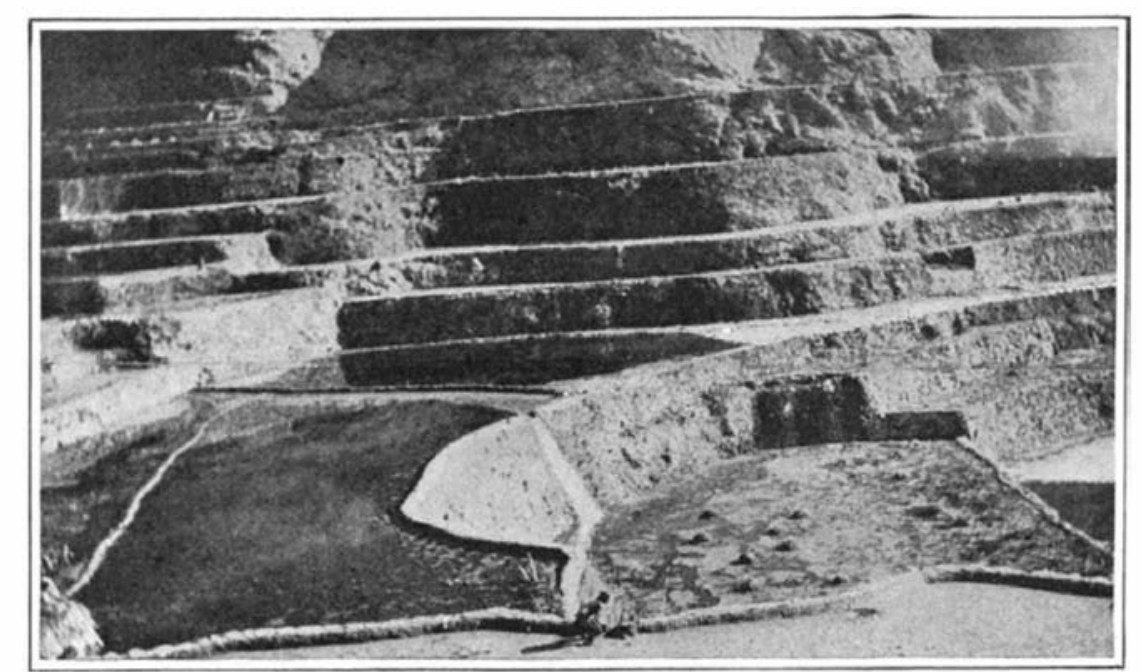

Rice terraces near Banaue.

The figure in the foreground gives an idea of the magnitude of the structure. The walls are from 6 to 18 feet high.

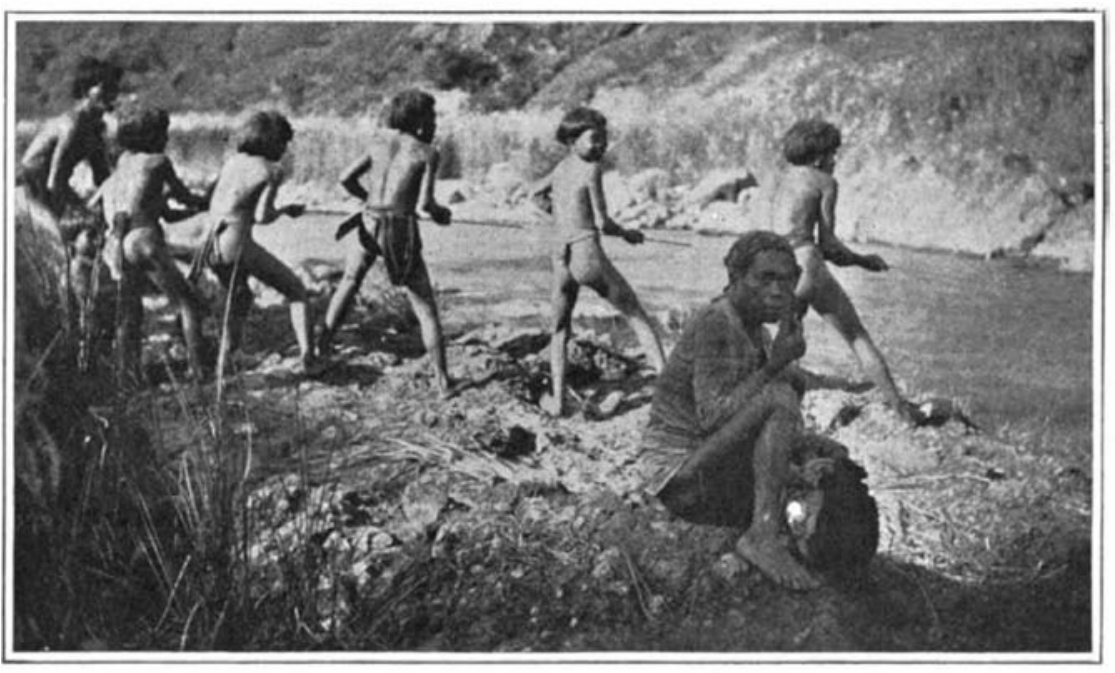

Ifugao boys pulling passengers across a swift mountain stream on a bamboo ferry.
The finest of the Ifugao terraces lie along the sides of a steep canyon between the native settlements of Quiangan and Banaue in Nueva Viscaya Province. Here the Ifugaos have constructed these rice paddies like giant steps up the steep canyon sides to a height of 1,200 feet or more, and it is said they extend into a secondary range of hills, making the extension almost 3,000 feet. The distance between Quiangan and Banaue is about twelve miles, and is negotiated by a winding foot path that in some places will not allow two to pass. In one place the trail extends along the retaining wall of a rice paddy. This wall is 18 inches wide and there is a sheer drop of 70 feet below to the next paddy. The paddy varies from 8 to 40 feet in width and is approximately 300 feet long following the contour of the canyon. Some of the terraces, each of which is flooded with water before the rice planting in the early spring, are wonderful feats of engineering. At times they follow the contour of a canyon for as great a distance as half a mile without varying scarcely two inches, say, from a dead level. The retaining walls of each terrace are built to be about fifteen inches above the water level, and when the terraces are flooded it is seen that this condition has been precisely complied with. The retaining wall of each terrace forms one side of the rice paddy, and the hill or canyon on the other side. At the point where the paddy meets the canyon side, the retaining wall of the terrace next above begins, so that there is no canyon so steep that it does not present an unbroken succession of terraces. All retaining walls are perpendicular and built at right angles to the level of the earth.

In the art of intensive cultivation the Ifugaos have progressed far. They irrigate and fertilize in a single operation. Water (Concluded on page 116.)

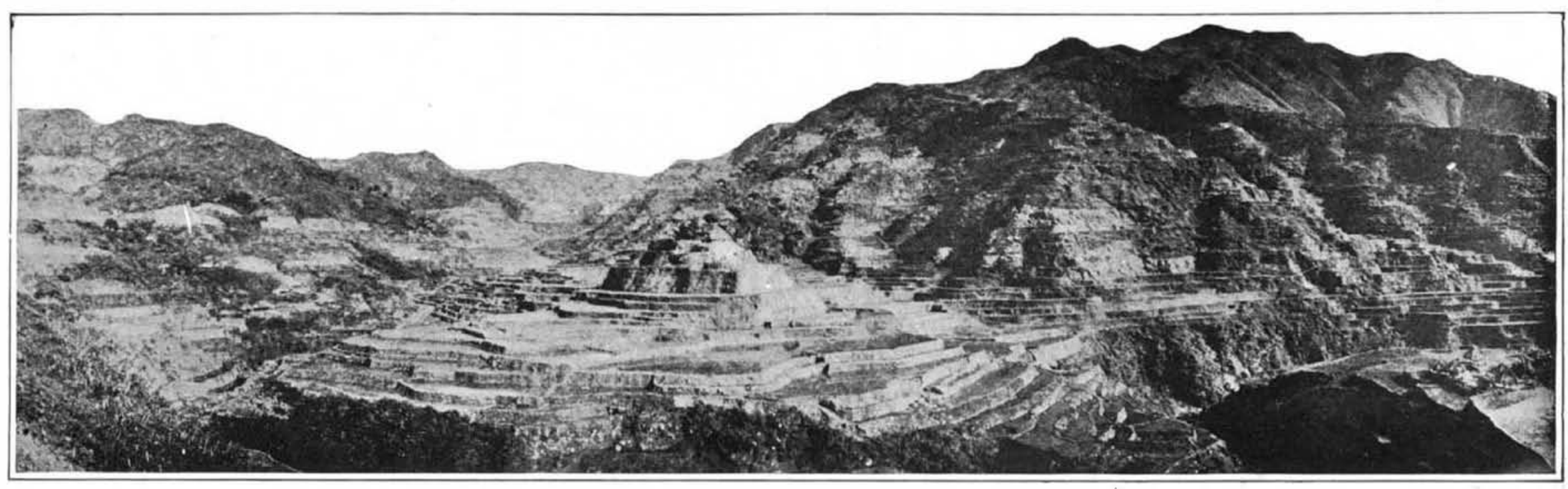

Marvelous terraced pyramid of the Ifugao savages in Nueva Viscaya Province, Luzon. Note the settlement and houses at the top of the pyramid. 
PENNSYLVANIA

RAILROAD

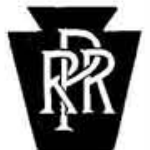

\section{Off for Cleveland!}

Cleveland is 579 miles from New York, but you can reach the Lake City in 14 hours by using the train leaving Pennsylvania Station at 6.32 P. M. The train arrives in Cleveland at 7.30 A. M., in time for breakfast before business. If you are destined to the residential section, leave the train at the Euclid A venue Station; if otherwise, at the Union Station on the lake front. The train is limited and affords excellent service. There is, of course, a well-appointed dining car serving dinner. A club car suggests smoke and refreshment and companionship. As a part of its equipment there is also a barber, who tidies up men's clothes, and a bath.

The observation and library car suggests its own purpose. It is open to all passengers and is a social exchange, a reading room and an outlook on the passing scenery. A ladies' maid and a manicurist serve the passengers. Drawing-rooms or state-rooms may be chosen by those who wish more seclusion than the berth affords.

This train is one of the famous trains of the land, and it is a great favorite with travelers between Cleveland and New York.

The excellence of its equipment and the timeliness of its schedule make it so.

The time table shows five other good trains to Cleveland leaving at convenient hours.

TANKS and of All Sizes COWERS Purpose

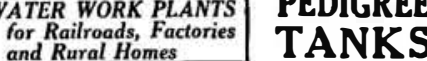
Write for
$\substack{\text { Circular } \\ \text { "N. F.S." The Baltimore Compan } \\ \text { Baltimore, Md. }}$

Rider Agents Wanted

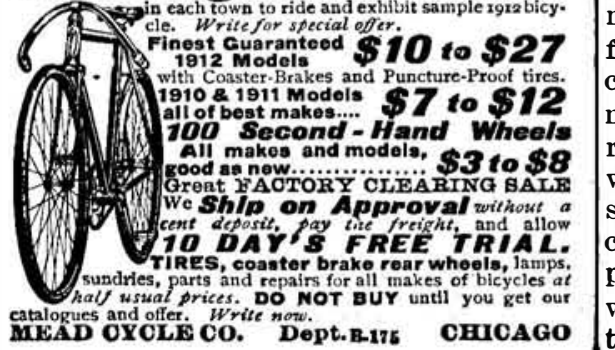

Across the Atlantic by Aeroplane
(Concluded from page 106) treme views as to the type of machine best
fitted to make the attempt. Some believe fitted to make the attempt. Some believe chief consideration in the design since a speedy machine would lessen the time of transit and require less fuel on that account. Others believe that a slow, large-
surface machine would be more reliable. surface machine would be more reliable,
since it would carry more weight per since it would carry more weight per
horse-power than the faster design. The writer believes that a happy mean of the opposed extremes will best subserve the end in view; that is, the machine should
be sufficiently engined relatively to its resistance, so that a speed of flfty miles per
hour will be insured in order to afford control in gusty winds. This speed is possible, together with a surface adequate to carry a very heavy load efficiently. In other words, if you increase an acrothe resistance increases in such rapid proportion that weight has to be added to the aeroplane in greater proportion for long voyages, and in several directions, i. e the greatly increased horse-power re-
quired in order to overcome the increased quired in order to overcome the increased
resistance due to the increase of speed reresistance due to the increase of speed re-
quires extra weight in engine and fuel. The parts of the machine also should be The parts of the machine also should be
heavier in order to stand the increased strains. On the other hand, a largesurface machine may be relatively inefficient by reason of its slowness and ver dangerous by reason of sluggishness i control.

A machine of the general design shown in the illustration could have a span of one hundred feet and a chord of ten feet, could be propelled by flve fifty-horsepower Gnome engines geared down to two per hour, and carry 7,500 pounds of weight, 4,500 pounds of which would be a "useful load." This would allow the ician and sufficient oil and fuel to sustain the aeroplane at fifty miles per hour for thirty-six hours, or over a course of 1,800 miles in still air. Five fifty-horse-
power Gnome engines could be fitted and power Gnome engines could be fitted and all used at the same time to attain alti-
tude with a full load. The fifth engine tude with a full load. The fifth engine
could be stopped by throwing it out of could be stopped by throwing it out of
gear with a friction-disk clutch, and four engines would sustain the weight of the machine until sufficient of the fuel load
had been consumed to lessen the angle of had been consumed to lessen the angle of
incidence and decrease the head resistance, when another engine could be
stopped. In this way the power would not stopped. In this way the power would not be wasted and every drop of fuel could be made to count for the end of the voyage.
It might even be possible to sustain the machine with only two engines going after most of the fuel was consumed and if the aeroplane was at sufficient altitude to a ford a slight assistance by gravity.

The sketch shows a portion of the fuselage inclosed and directly under the center of pressure, where sufficient oil so arranged as to leave a two-foot passage fore and aft from the cabin, just under the operator's cockpit to the engine room. The extreme width of the fusilage is eight feet, and affords six feet clear head room. The engines are placed on both sides of the inclosed central passage so that the mechanician would find each engine very accessible. Hence the engines will always be working in free air. The transmission could lead to a central shaft and thence by incased
patent chain to the shafts of the two tractor screws. The friction clutch would posed vegetable matters, ashes, black aline in mechanician to throw any en- luvial soil, and manure, and is then congine in or out of operation at will, so ducted to the topmost rice terrace, carry plugs should be as simple a matter during which is evenly distributed. There the passage as it would be at rest. If thus no part of a rice paddy which is not anything special went wrong with an en- fertilized. From the topmost terrace the gine the mechanic could have the help water flows through a gap in the retainmatter of fact those of us who have used carrying fertilizing matter in suspension. Gnome engines under the care of expert Most of the work in the paddies is done by mechanicians know that a 36-hour run the women, who wade about stirring up mechanicians know that a 36-hour run the women, who wade about stirring up
for a fifty-horse-power Gnome engine the sediment. Sometimes the rice straw clean and in otherwise good condition is of a harvested crop is covered over with occasion for the least worry. I should dirt and allowed to rot. The result proreally be surprised if with five engines it duces the finest rice raised in the Philipspark plug in the entire trip. In a ma- experts, of practically perfect form. chine so large as the one illustrated the $\begin{aligned} & \text { Ranchers in the west occasionally run a } \\ & \text { Ranction }\end{aligned}$ passage fore and aft of the mechanician irrigating ditch through fertilizing matter would hardly be perceptible to the con-
trol of the operator.
Labor on the retaining wall
The resistance of such a machine should the form throughout and since the sinThe aspect ratio is excellent, and the ord is not so deep that one need The controls of the aeroplane, although

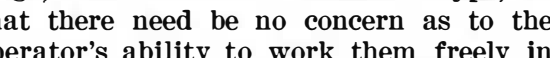
usty winds. r. Glenn Curtiss the use of a central either of these floats would make first-
class lifeboats in case of emergency and that the superstructure of the hydrofrom the float. The lines of the floats principle being superfluous, where sou ave an aeroplane to lift your floats clear the water.

ater in mid-ocean this could be acater without extreme risk, and unles plane could get into the air again with It is practically certain that were an main in the air for thirty hours pointed tude of about 5,000 feet, the air passage accomplished. A height of 5,000 feet would furnish an atmosphere comparaand clear of all fog, so that with a polari one would not need to depend on the comalso give one an extended horizon (80 hardly be a period on the passage over ssel would not be within the 160 -mil direction. and the steamers could report the A glance at a pilot chart for the North will show there is a very dependable ents, and it is safe to rely upon a conA to the wind currents.

ohns at daybreak. ude that the transatlantic aerial voyage orth considering, and we may wish sucass to the chairman of the Royal Aero
lub, Roger K. Wallace, in his efforts to nnection of England and America.

Savage Irrigation in Luzon Labor on the retaining walls is done boat or float, but he is now converted to
the two-float type and believes that
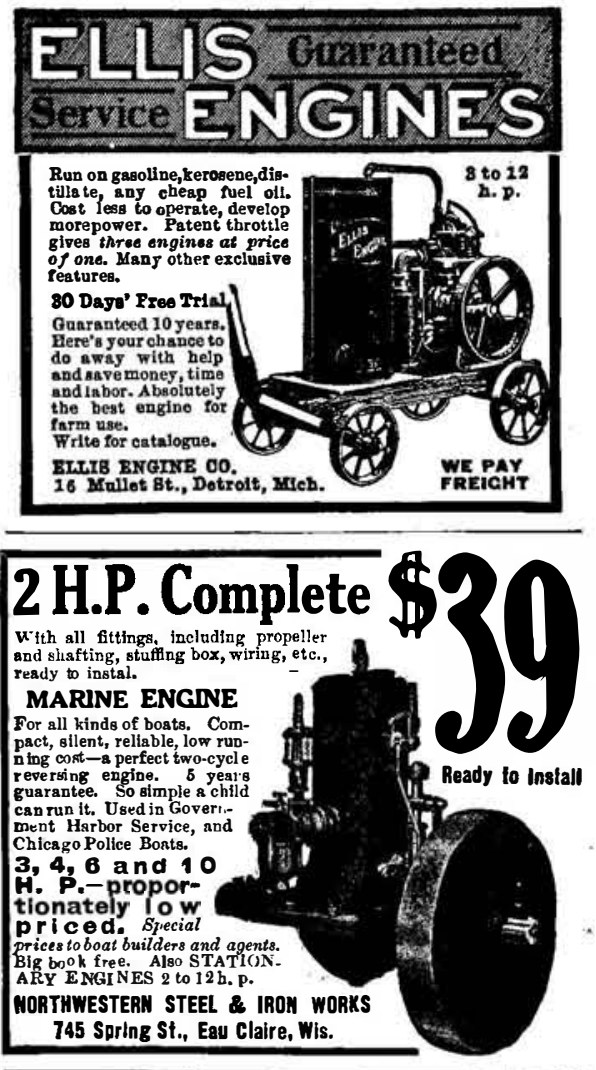

$\$ 150$ KERMATH $\$ 150$
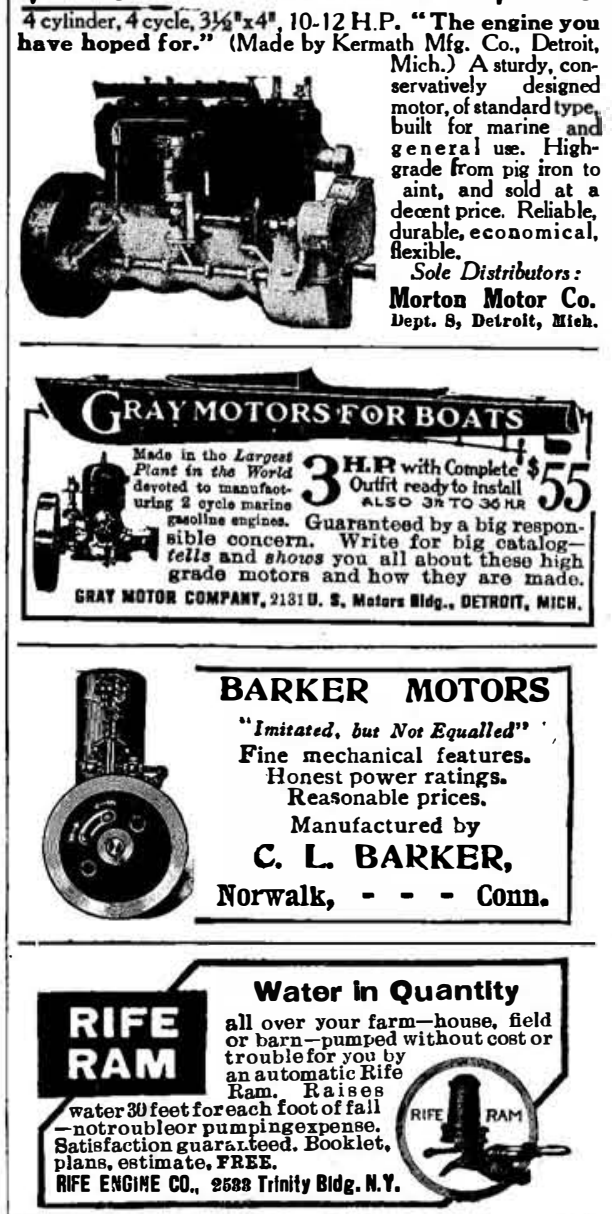

Magical Apparatus. 25c. Parlor Tricks Catalogue, free.
MARTINEA \& co.. Mifrs, 493 Sistb Ave., New York 8) Print Your OWW

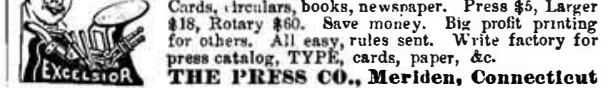

Learn Watchmaking

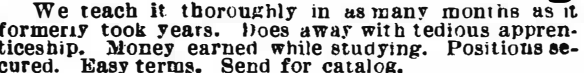
Tr. LOCIB WATCHMARING BCHOOL. Bt. Loula, Mo.
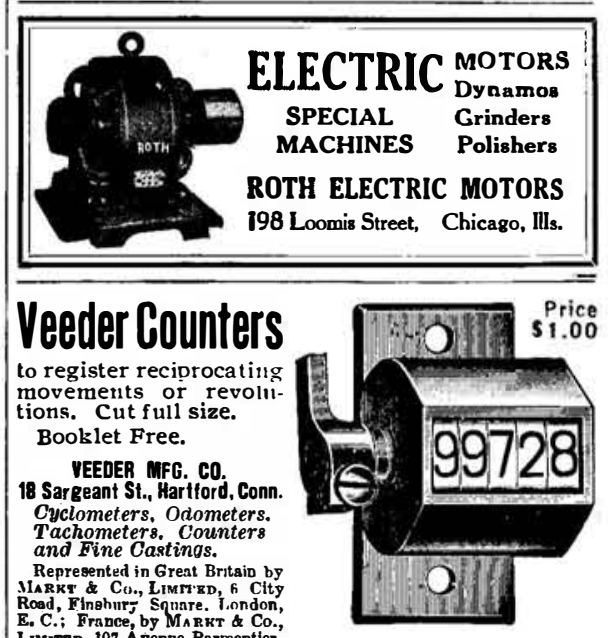

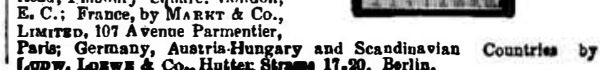



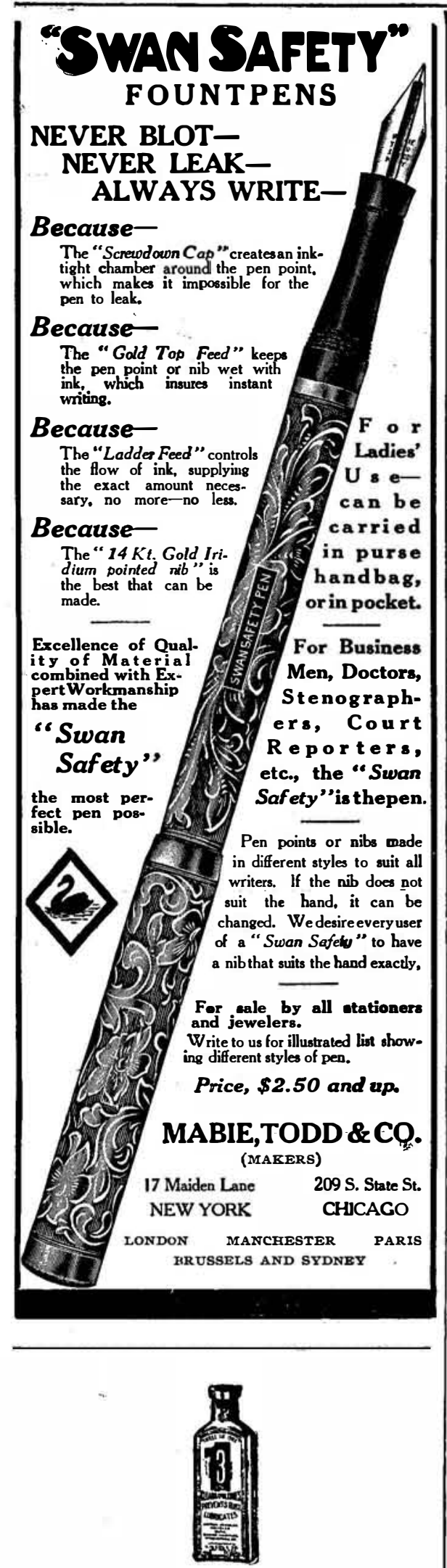

"3-in-One" is a household oil, lubricating, cleaning, polishing and preventing rust-

Try for oiling sewing machines, clocks,
locks, guns, bicycles, etc. Try for cleaning locks, guns, bicycles, etc. Try for cleaning
and rolishing any furniture; fine pianos, and polishing any furniture, fine pianos,
old tables, etc. Try for preventing rust on any metal surface. Trial bottle sent free.
3 IN 1 OIL CO., $42 \mathrm{AZ} \mathrm{H}$, Broadway, New York.

\section{Two Gents a Week Pays Wash Bill!}
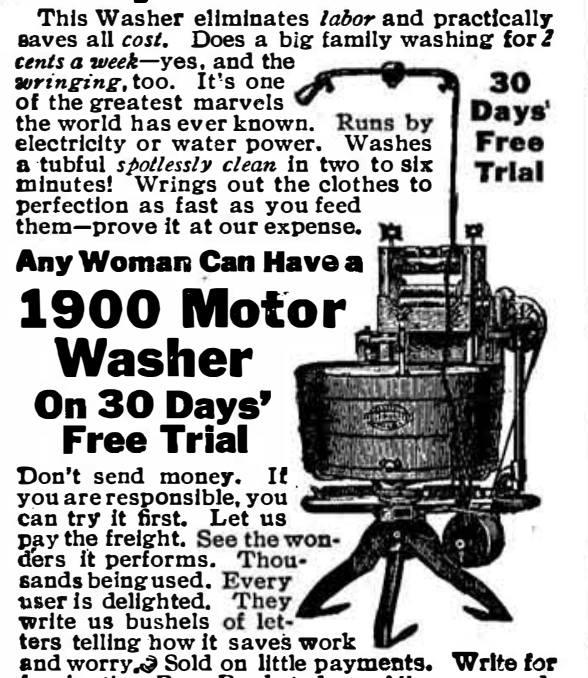

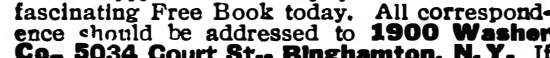
pou live In Canada; address Canadlan 1900
Washer Co., 355 Yonge St., Toronto, Canada by the Ifugao warriors, who place the stones gathered in the ravine beds one above another somewhat in the fashion
that a New England farmer builds a ston that a New England farmer builds a stone fence. They are provided with wooden spades, knives and spears, which they use re forged by themselves or else gained by trade from the Benguet Igorrotes. In some places they have carved down the rock which appears to be a sandstone or companying panorama pictures shows an isolated hill in the middle of the marvelous canyon referred to, carved into errace form and surrounded by terrace on all sides. At the summit of the hill is seen an Ifugao settlement commanding baronial view of the country. This pyramid rises probably eight hundred feet ane the stream in the gorge below. The Singer Building in New York, if set in the gorge, would be practically lost to with the work of the head-hunters, for the mountains are so sculptured that in places they seem almost to have been uilt up by artificial means.

The gorge here shown is densely cultvated throughout its entire length. Every ravine leading into it shows a sucew years ago each If gago settlement wast in a state of feud with its neighbor. Setlements as close as two miles from one
nother were hostile. For generations the warriors of Quiangan and Banaue had engaged in raiding the opposing village for heads. It is said that early in the last century the Spanish governor-general of the Philippines sent a detachment of troops to subdue these hillsmen, but at the soldiers were decimated by $t$ head-hunters, who lay behind their reat the invaders as they marched throug the country in single file. Last year, according to Philippine Commissioner Worcester's report, there was no head ta
reported among the 170,000 Ifugaos.

The photographs here shown were take
The y the writer in an overland trip throug Luzon between Manila and its northernnost port, Aparri. The railroad is left and Dagupan Railway, and thence tl ourney proceeds inland. Contrary general opinion, the journey through the Cordillera Mountains is not hard or danevery moment and if made well in ad vance of the rainy season the streams ar easily forded.

The Heavens in February

\section{(Concluded from pase 110)}

surface can be calculated-or, at least, a value can be obtained which is probably sing and Scheiner of Potsdam have calculated that the surface temperature of stars which resemble Sirius in spectrun (The on the avera, about 10,000 de (The Sun's surface temperature is about little under 4,000 degrees, and the hot test ordinary furnaces hardly reaci 2,000 degrees.)

If this is true of Sirius, its surface would give out about eight times as much light per square mile as the Sun's dex As the total light of Sirius is twenty-fou times that of the Sun, it would have three times the Sun's superficial area, and
hence about one and three-quarters times hence about one and three-quarters times the Sun's diameter. This would make its bulk about five times that of the Sun and its density about half as great. To get similar data for the faint companion is more difficult, as its spectrum cannot be observed, owing to diff used light from its brilliant neighbor. We may, The companion of Sirius is almost equal to the Sun in mass. It is almost certainly not more than fifteen times as dense as the Sun (for this would make it dense than ten times as dense. On the latter hypothesis, its surface would be about one-fifth that of the Sun. But it gives out only as much light as the Sun and hence must emit only $\frac{1}{80}$ as much light per square mile. According to phys cal theory, this would demand
perature of about 3,000 degrees.

perature of about 3,000 degrees.

If on the other hand we assume that the
companion equals the Sun in density
Building a Boat is Great Sport

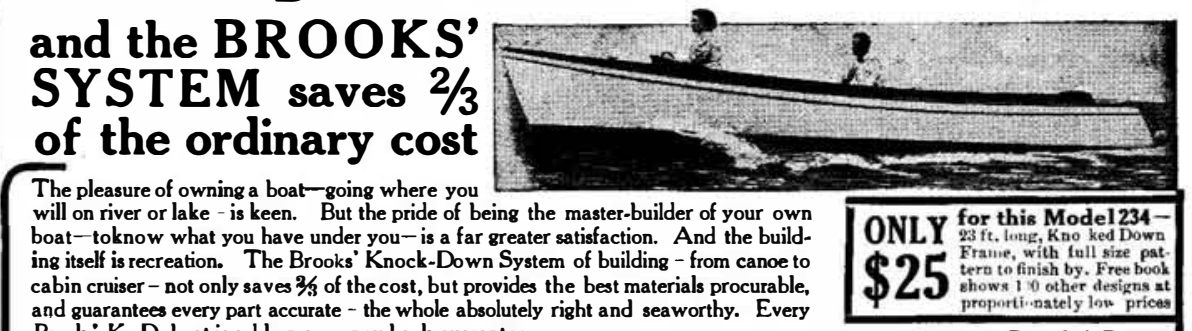
Brooks' K. D. boat is sold on a money-back guarantee.
.

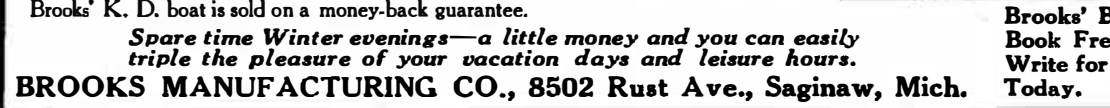
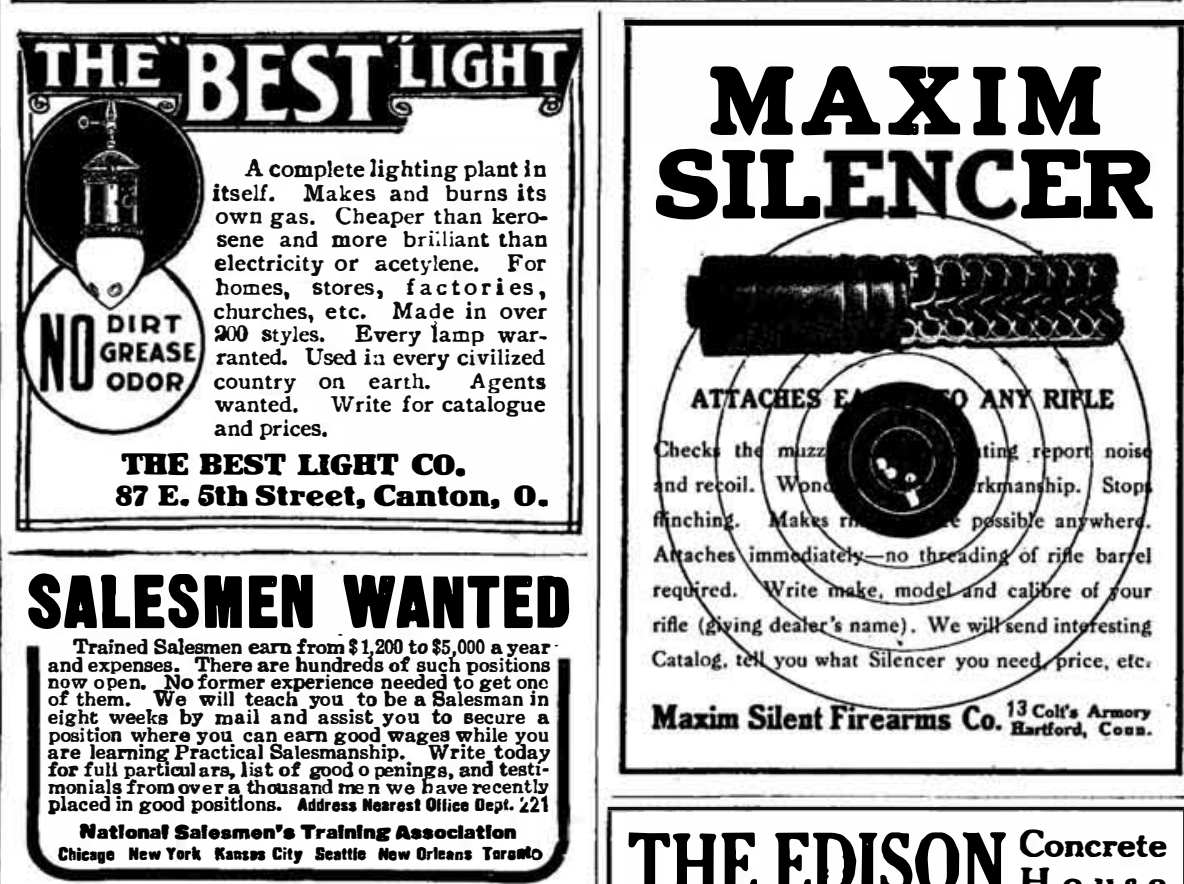

A Home-Made 100-Mile Wireless Telegraph Outfit II Read Scientific Amer-

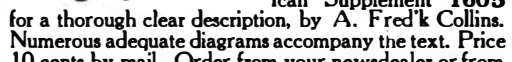
MUNN \& CO., Inc. 361 Broadway, New York

\section{The Montelair}

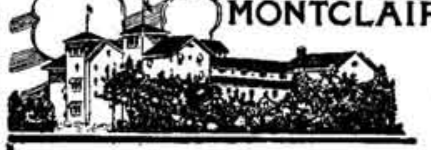

HOME hotel for the family, the a residence within an hour from $\mathrm{New}$ York and enjoy the delights of country, elevation, rest and environments. This is what the Montclair Hotel offers. It is operated on the American plan, has grillroom with facilities for private parties, banquets, dances under the

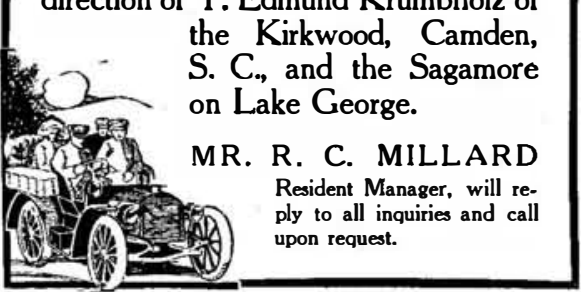

THE EDISON Concrete \begin{tabular}{l} 
How it is constructed, how much it will cost, is it prac- \\
tical from an architectural and engineering standpoint? \\
These and other important questions relating to the struc- \\
ture are discussed in a good, thorough, illustrated article \\
publishedin Scientific $A$ merican Supplement 1685 . Price \\
10 cents by mail. Order from your newsdealer or from \\
\hline MUNN \& CO., Inc., Publishers, 361 Broadway, N. Y.
\end{tabular} IIEKIDIIWCOD

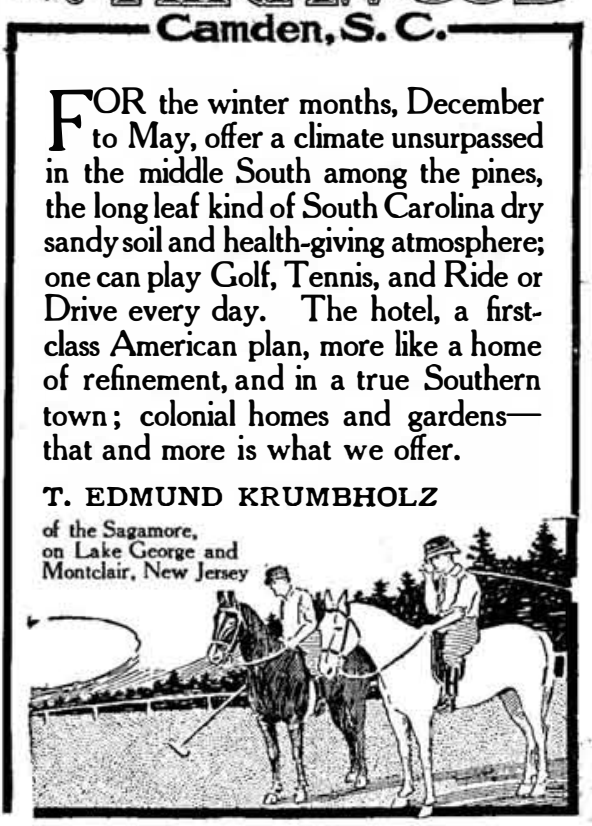
Come to Florida and Farm all the Year. itheras.

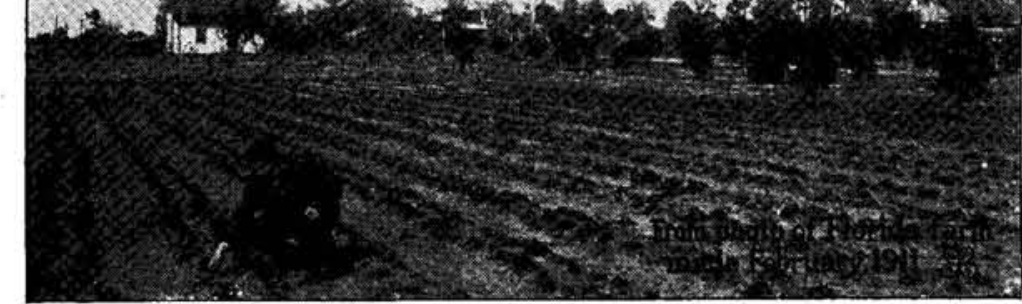

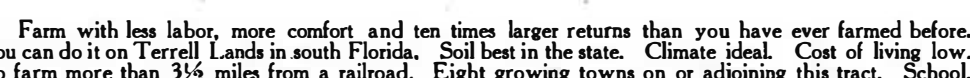

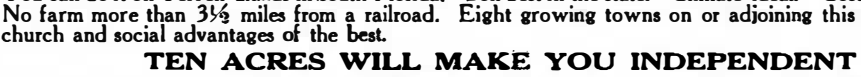
You can work them every month in the year, raising two to four crops which will return you $\$ 150$

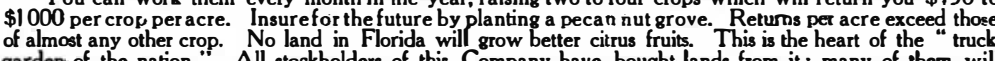

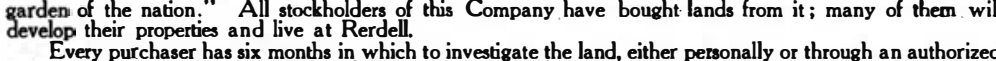

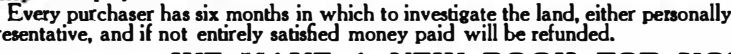

It is beautifully illustrated. It telle all about Terenll Lands, how you can secure a farm or a winter
me there on easy letrms. lit also gives full details of a safe, sound investment plan for you if you do no TERREU LAND AND DEVELOPMENT CO. Box 113. RERDELL (Via Terrell) FLORIDA 